Evelyn A. Huhn*, Nadine Massaro, Simone Streckeisen, Gwendolin Manegold-Brauer, Andreas Schoetzau, Sven M. Schulzke, Bettina Winzeler, Irene Hoesli and Olav Lapaire

\title{
Fourfold increase in prevalence of gestational diabetes mellitus after adoption of the new International Association of Diabetes and Pregnancy Study Groups (IADPSG) criteria
}

DOI 10.1515/jpm-2016-0099

Received March 16, 2016. Accepted July 7, 2016. Previously published online August 10, 2016.

\section{Abstract}

Background: The aim was to evaluate the influence of the new International Association of Diabetes and Pregnancy Study Groups (IADPSG) guidelines for screening of gestational diabetes mellitus (GDM) on GDM prevalence in a cohort from a Swiss tertiary hospital.

Methods: This was a retrospective cohort study involving all pregnant women who were screened for GDM between 24 and 28 weeks of gestation. From 2008 until 2010 (period 1), a two-step approach with 1-h $50 \mathrm{~g}$ glucose challenge test (GCT) was used, followed by fasting, 1- and 2-h glucose measurements after a $75 \mathrm{~g}$ oral glucose tolerance test (OGTT) in case of a positive GCT. From 2010 until 2013 (period 2), all pregnant women were tested with a onestep $75 \mathrm{~g}$ OGTT according to new IADPSG guidelines. In both periods, women with risk factors could be screened directly with a $75 \mathrm{~g}$ OGTT in early pregnancy.

Results: Overall, 647 women were eligible for the study in period 1 and 720 in period 2. The introduction of the

*Corresponding author: Evelyn A. Huhn, Department of Obstetrics and Gynaecology, University Hospital Basel, Spitalstrasse 21, 4031 Basel, Switzerland, Tel.: +416155651 44,

E-mail: evelyn.huhn@usb.ch.

http://orcid.org/0000-0001-5382-1353

Nadine Massaro: Department of Surgery, Hospital Dornach, Dornach, Switzerland

Simone Streckeisen: Department of Anaesthesiology, Cantonal Hospital Baselland, Liestal, Switzerland

Gwendolin Manegold-Brauer, Andreas Schoetzau, Irene Hoesli and Olav Lapaire: Department of Obstetrics and Gynaecology, University Hospital Basel, Basel, Switzerland

Sven M. Schulzke: Department of Neonatology, University of Basel Children's Hospital, Basel, Switzerland

Bettina Winzeler: Department of Endocrinology and Diabetes, University Hospital Basel, Basel, Switzerland
IADPSG criteria resulted in an absolute increase of GDM prevalence of $8.5 \%$ (3.3\% in period 1 to $11.8 \%$ in period 2 ). Conclusions: The adoption of the IADPSG criteria resulted in a considerable increase in GDM diagnosis in our Swiss cohort. Further studies are needed to investigate if the screening is cost effective and if treatment of our additionally diagnosed GDM mothers might improve short-term as well as long-term outcome.

Keywords: Gestational diabetes mellitus; IADPSG criteria; oral glucose tolerance test; pregnancy; prevalence; screening.

\section{Background}

The introduction of the new International Association of Diabetes and Pregnancy Study Groups (IADPSG) screening criteria in 2010 [1] resulted in a massive increase in women who need intensive counseling and treatment for gestational diabetes (GDM) worldwide. The new thresholds were based on results of a large prospective cohort study, the Hyperglycemia and Adverse Pregnancy Outcome (HAPO) study [2]. The aim of the HAPO study was to investigate the degree of maternal glycemia with regard to adverse perinatal outcome like large-for-gestational-age (LGA) infants, neonatal hypoglycemia and cesarean section rate. The results showed no clear threshold for the occurrence of adverse outcomes, but rather a continuous increase of these outcomes across the range of glucose concentrations after universal screening with $75 \mathrm{~g}$ oral glucose tolerance test (OGTT) between 24 and 28 weeks of gestation. The thresholds were defined by odds ratios of 1.75 for a macrosomic child or clinical hyperinsulinemia (cord blood c-peptide). This screening approach was at first widely accepted. The Swiss Society for Endocrinology and Diabetology (SGED) recommended in 2009 the use of the IADPSG criteria [3], followed by the Swiss 
Society of Gynecology and Obstetrics (SGGG) in 2011 [4]. The American Diabetes Association (ADA) adopted these thresholds in 2010 and the World Health Organization (WHO) in $2013[5,6]$. The IADPSG criteria resulted in a considerable increase in the prevalence of GDM up to 45.3\% [7] depending on ethnic background, obesity, mean maternal age at delivery and other factors. High resulting prevalences of GDM in some countries led to conflicting opinions about treatment evidence of mild GDM cases and cost effectiveness of the universal screening approach [8]. The diagnostic changes in GDM screening were made in the background of epidemic increases in obesity and diabetes type 2 worldwide. Expectations are high that by widening the diagnostic window, both short- and long-term outcome for mothers and their babies could be optimized.

The primary aim of our study was to analyze GDM prevalence before and after the introduction of the IADPSG criteria in a Swiss tertiary center. Secondly, we aimed to clarify if the change in screening approach identified additional women at risk of adverse perinatal outcome with emphasis on the detection of LGA infants.

\section{Methods}

\section{Study population}

This analysis is a retrospective cohort study involving all pregnant women who underwent screening for GDM at the University Women's Hospital of Basel between June 2008 and January 2013 and who delivered at $>22$ completed weeks of gestation. The study was conducted in compliance with the Helsinki Declaration. All patient protection criteria were complied. According to local regulations international review board consent was not required for this type of study. Exclusion criteria were multiple gestations, screening values conclusive for pre-existing diabetes mellitus (fasting glucose value $\geq 7.0 \mathrm{mmol} / \mathrm{L}$ ( $126 \mathrm{mg} / \mathrm{dL})$ and/or 2-h glucose value $\geq 11.1 \mathrm{mmol} / \mathrm{L}$ ( $200 \mathrm{mg} / \mathrm{dL})$ after $75 \mathrm{~g}$ OGTT) at any time of pregnancy, "late" screening $>28$ weeks of gestation, incomplete data set or delivery elsewhere. Only the first pregnancy was included in the study if a woman delivered more than once during the study period.

\section{GDM screening strategies}

During the observational period, GDM screening consisted initially of a 2-step screening approach between June 2008 and September 2010 according to the recommendations of the Canadian Diabetes Association (CDA) in 2008. The first step involved a universal screening between 24 and 28 weeks of gestation with a 1-h 50 g glucose challenge test (GCT), which could be administered in a non-fasting state. A glucose value $\geq 7.8 \mathrm{mmol} / \mathrm{L}$ ( $140 \mathrm{mg} / \mathrm{dL}$ ) was interpreted as a screening positive result. All women who screened positive then underwent a fasting, 2-h $75 \mathrm{~g}$ OGTT with fasting, 1-h and 2-h blood glucose thresholds of $\geq 5.3 \mathrm{mmol} / \mathrm{L}(95 \mathrm{mg} / \mathrm{dL}), \geq 10.0 \mathrm{mmol} / \mathrm{L}$
(180 mg/dL) and $\geq 8.6 \mathrm{mmol} / \mathrm{L}$ ( $155 \mathrm{mg} / \mathrm{dL})$, respectively. The diagnosis of GDM was established if women had at least two or more values exceeding the thresholds values.

In accordance with the SGED recommendations of 2009 [3], the new one-step screening approach based on the HAPO study from 2008 [2] were introduced in our perinatal center in October 2010. A 28-month period between June 2008 and September 2010 with the two-step screening were compared with the subsequent 28-month period from October 2010 until January 2013 with the new onestep screening approach. All women were screened directly with the $75 \mathrm{~g}$ OGTT with fasting, 1-h and 2-h blood glucose values with thresholds of $\geq 5.1 \mathrm{mmol} / \mathrm{L}(92 \mathrm{mg} / \mathrm{dL}), \geq 10.0 \mathrm{mmol} / \mathrm{L}(180 \mathrm{mg} / \mathrm{dL})$ and $\geq 8.5 \mathrm{mmol} / \mathrm{L}$ ( $153 \mathrm{mg} / \mathrm{dL}$ ), respectively, between 24 and 28 weeks of gestation. Screen-positive women were those who had at least one glucose value above the recommended threshold.

In both screening periods, some women with multiple risk factors underwent a $75 \mathrm{~g}$ OGTT in early pregnancy to reduce falsenegative tests. Risk factors were $\mathrm{BMI} \geq 30 \mathrm{~kg} / \mathrm{m}^{2}$, Asian, African or Hispanic ethnicity, physical inactivity, polycystic ovary syndrome, intake of diabetogenic drugs, diabetes type 2 of a first grade relative, previous birth of a macrosomic infant or previous GDM. All early screen-negative women with risk factors had to complete a second $75 \mathrm{~g}$ OGTT between 24 and 28 weeks of gestation. All glucose measurements were performed in venous plasma.

\section{Follow-up and delivery management}

All women who screened positive for GDM were followed up by a nutritionist and a diabetes nurse in contact with a diabetologist and had regular appointments at our obstetrical outpatient clinic at 2-4-week intervals depending on the clinical condition, glucose values and ultrasound findings. Women who failed to meet the targeted glucose values after 1-2 weeks of diet management were treated with insulin according to the SGED guidelines [3]. No oral antiglycemic agents were prescribed. Labor induction was considered in women with GDM between 38 and 41 weeks of gestation dependent on insulin/diet management, glycemic control 2-4 weeks before labor, clinical condition and estimated fetal weight. If additionally fetal macrosomia was suspected, labor induction, expectant management or primary cesarean section was discussed with the parents according to the recommendations by the American College of Obstetriciants and Gynecologists (ACOG) [9].

\section{Data collection and analysis}

Data were extracted from the obstetrical, pediatric and laboratory datasets and cross matched. The following data were collected: GCT and OGTT test results, gestational age at the time of screening, ethnicity, demographic characteristics, general, medical and obstetric history of the mother, GDM management, and obstetric and neonatal outcome. Maternal pre-pregnancy weight was self-declared by the women during the first pregnancy visit. Maternal weight at the time of delivery was measured upon arrival of the women at the delivery ward. Pre-pregnancy and delivery weight were ranked according to the WHO classification system for body mass index (BMI). Gestational weight gain was calculated as the difference between prepregnancy and delivery weight and was ranked in categories "below recommended", "met recommended" and "above recommended" 
gestational weight gain according to the Institute of Medicine (IOM) guidelines of 2009 (recommended weight gain according BMI class: underweight $\left(<18.5 \mathrm{~kg} / \mathrm{m}^{2}\right): 12-18 \mathrm{~kg}$; normal $\left(18.5-24.9 \mathrm{~kg} / \mathrm{m}^{2}\right): 11.5-$ $16 \mathrm{~kg}$; overweight $\left(25.0-29.9 \mathrm{~kg} / \mathrm{m}^{2}\right): 6.8-11.4 \mathrm{~kg}$; obese $\left(\geq 30.0 \mathrm{~kg} / \mathrm{m}^{2}\right)$ : $5-9 \mathrm{~kg}$ ) [10]. Birth weight and length were collected from the delivery and neonatal records and weight percentiles were calculated based on gestational age. LGA infants were defined as neonates with a birth weight $\geq 90$ percentile. Macrosomia was defined as neonates with a birth weight $\geq 4000$ g. GDM prevalence, diet/insulin management and pregnancy outcomes of the screening positive and negative women in each period were compared. Neonatal hypoglycemia was defined as a glucose value of $<2.5 \mathrm{mmol} / \mathrm{L}$ in infants born $\geq 34$ weeks of gestation according to the Swiss Society of Neonatology.

\section{Statistics}

Categorical and continuous variables were presented as mean (SD) or counts (percentages). Study groups were compared using the $\chi^{2}$ test or the independent $t$-test as appropriate. If the expected frequency was $<5$, Fisher's exact test was used. A level of significance of $P \leq 0.05$ was considered as significant. All statistical analyses were performed with the statistical software R version 3.1.1 [11].

\section{Results}

\section{Effects of IADPSG criteria on GDM prevalence}

A total of 1687 women were screened for GDM during the study period. In the end, 1376 women with singleton pregnancies were eligible to participate in the study (Figure 1): 651 women in screening period 1 and 725 women in screening period 2. Four women $(0.61 \%)$ in screening period 1 and five women $(0.69 \%)$ in screening period 2 had glucose values conclusive for pre-existing diabetes. In screening period 1, 12 women $(1.9 \%)$ were tested in early pregnancy directly with a one-step $75 \mathrm{~g}$ OGTT because of multiple risk factors. Two women were diagnosed to have GDM by early screening. Eighteen percent of all 1-h $50 \mathrm{~g}$ GCTs (115/635) were interpreted as screening positive in 24-28 weeks of gestation. The subsequent $75 \mathrm{~g}$ OGTT in the $50 \mathrm{~g}$ GCT screen-positive group was found to be pathologic in 16.5\% (19/115). This screening approach resulted in an overall GDM prevalence of 3.3\% in screening period 1 . In screening period 2, $70(9.7 \%)$ women were screened in early pregnancy before 24 weeks of gestation. Nineteen of these 70 women (27.1\%) were diagnosed early in pregnancy with GDM. Additionally, 66 of 701 (650 first plus 51 second time $75 \mathrm{~g}$ OGTT) 75 g OGTTs in 24-28 weeks of gestation had pathologic glucose values (9.4\%). This screening approach resulted in a prevalence of $11.8 \%$ in screening period 2 . Forty-nine percent of women with GDM were diagnosed by fasting glucose level surpassing the threshold value of $\geq 5.1 \mathrm{mmol} / \mathrm{L}$ in early and late screening (Table 1). Additionally, $35.3 \%$ and $15.3 \%$ of women were found to have GDM based on the glucose values over the recommended 1- and 2-h IADPSG threshold.

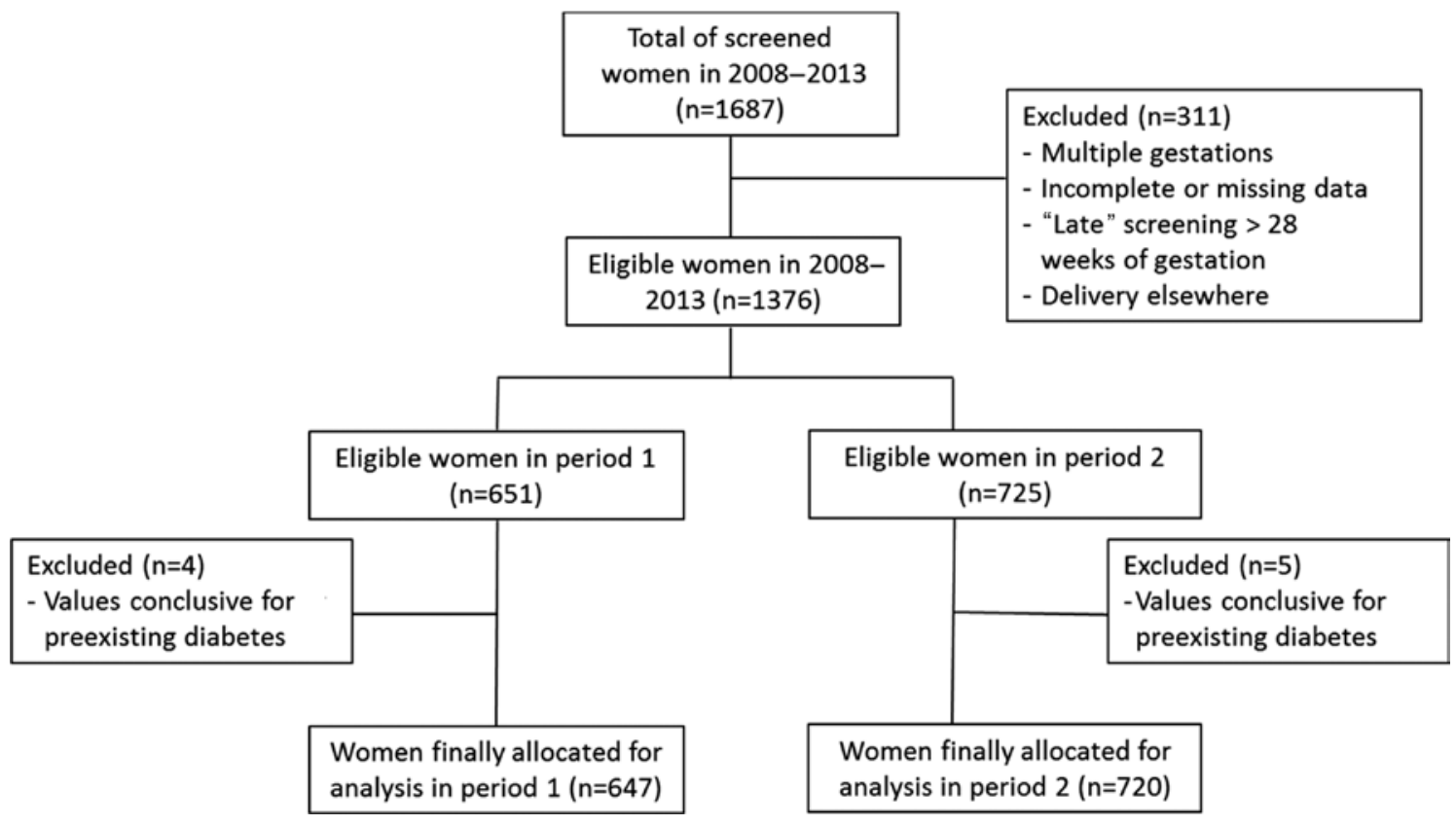

Figure 1: Flow chart of included and excluded women in both screening periods. 
Table 1: IADPSG thresholds, cumulative proportion and total proportion of each threshold to the diagnosis of GDM in period 2 (early and late OGTT $75 \mathrm{~g}$ ).

\begin{tabular}{lrrr}
\hline $\begin{array}{l}\text { Glucose } \\
\text { value }\end{array}$ & $\begin{array}{r}\text { Glucose } \\
\text { threshold } \\
(\mathrm{mmol} / \mathrm{L})\end{array}$ & $\begin{array}{r}\text { Cumulative } \\
\text { proportion zthreshold } \\
(\%)\end{array}$ & $\begin{array}{r}\text { Proportion of GDM } \\
\text { cases dependent } \\
\text { on threshold (\%) }\end{array}$ \\
\hline Fasting & 5.1 & 5.8 & 49.4 \\
1-h & 10.0 & 10.0 & 35.3 \\
2-h & 8.6 & 11.8 & 15.3 \\
\hline
\end{tabular}

aProportion of GDM cases (in \%) dependent on threshold (the diagnosis is found when one value exceeds the threshold).

\section{Differences in patient characteristics and pregnancy outcomes}

More overweight and obese women were found to have GDM compared to non-overweight/obese women in period 1 as well as in period 2 (Table 2). No statistical differences were found in recommended weight gain per BMI group according to IOM, ethnicity or parity. The patient characteristics in both GDM groups in period 1 and 2 were not significantly different.

In screening period $1,38 \%$ of all women with GDM were treated with insulin due to elevated glucose values despite dietary management. Insulin therapy was initiated in $29 \%$ of the GDM group in screening period $2(\mathrm{P}=0.12$ between both GDM groups) (Table 3). Women with GDM tended to deliver more frequently via primary cesarean section in period $1(33.3 \%$ vs. $10.5 \%, P=0.04)$ and period 2 (27.4 vs. $16.1, \mathrm{P}=0.008$ ) than those without GDM; however, there were no differences in primary cesarean section rate between women with GDM in period 1 and 2. Gestational age at delivery, rate of preterm delivery and birth weights were not different between women with and without GDM in both periods or between women with GDM in period 1 and 2 as well as rate of macrosomia $(\mathrm{P}=0.16$ in period 1 , $\mathrm{P}=0.13$ in period 2 ) or $\mathrm{LGA}$ infants ( $\mathrm{P}=0.06$ in both periods)

Table 2: Characteristics of study groups in both periods.

\begin{tabular}{|c|c|c|c|c|c|c|c|}
\hline \multirow{2}{*}{$\begin{array}{l}\text { Period } \\
\text { Study group }\end{array}$} & \multicolumn{3}{|c|}{ Period $1(n=647)$} & \multicolumn{3}{|c|}{ Period $2(n=720)$} & \multirow{2}{*}{$\begin{array}{l}\begin{array}{l}\text { Comparison of GDM } \\
\text { groups in period } 1 / 2\end{array} \\
\text { P-value }\end{array}$} \\
\hline & $\begin{array}{l}\text { No GDM } \\
(n=626)\end{array}$ & $\begin{array}{r}\text { GDM } \\
(n=21)\end{array}$ & P-value & $\begin{array}{l}\text { No GDM } \\
(n=635)\end{array}$ & $\begin{array}{r}\text { GDM } \\
(n=85)\end{array}$ & P-value & \\
\hline Maternal age $\geq 35$ years (\%) & $160(26.0)$ & $4(19.0)$ & 0.65 & $166(26.2)$ & $24(28.2)$ & 0.79 & 0.82 \\
\hline BMI pre-pregnancy $\left(\mathrm{kg} / \mathrm{m}^{2}\right)$ & $23.8(6.39)$ & $28.2(5.87)$ & 0.003 & $23.6(4.95)$ & $27.7(6.24)$ & $<0.001$ & 0.99 \\
\hline BMI pre-pregnancy class (\%) & & & $<0.001$ & & & $<0.001$ & 0.60 \\
\hline Underweight & $35(6.0)$ & 0 & & $42(7.1)$ & 0 & & \\
\hline Normal & $401(68.9)$ & $6(30.0)$ & & $388(65.1)$ & $32(39.5)$ & & \\
\hline Overweight & $96(16.5)$ & $8(40.0)$ & & $108(18.1)$ & $23(28.4)$ & & \\
\hline Obese & $50(8.6)$ & $6(30.0)$ & & $58(9.7)$ & $26(32.1)$ & & \\
\hline BMI delivery $\left(\mathrm{kg} / \mathrm{m}^{2}\right)$ & $29.7(7.24)$ & $33.3(5.47)$ & 0.01 & $29.1(5.06)$ & $32.8(6.01)$ & $<0.001$ & 0.99 \\
\hline BMI delivery class (\%) & & & 0.15 & & & $<0.001$ & 1.00 \\
\hline Underweight & $1(0.2)$ & 0 & & 0 & 0 & & \\
\hline Normal & $95(16.8)$ & $1(5.3)$ & & $101(17.8)$ & $4(5.5)$ & & \\
\hline Overweight & $251(44.3)$ & $6(31.6)$ & & $278(49.0)$ & $24(32.9)$ & & \\
\hline Obese & $219(38.7)$ & $12(63.2)$ & & $188(33.2)$ & $45(61.6)$ & & \\
\hline Weight gain $(\mathrm{kg})$ & $15.6(6.17)$ & $13.9(7.61)$ & 0.34 & $14.8(6.02)$ & $13.2(7.06)$ & 0.10 & 0.98 \\
\hline Weight gain groups (\%) & & & 0.95 & & & 0.50 & 0.95 \\
\hline Below recom. & $110(20.0)$ & $3(15.8)$ & & $116(20.9)$ & $14(19.7)$ & & \\
\hline Met recom. & $167(30.4)$ & $6(31.6)$ & & $173(31.2)$ & $27(38.0)$ & & \\
\hline Above recom. & $272(49.5)$ & $10(52.6)$ & & $265(47.8)$ & $30(42.3)$ & & \\
\hline Ethnicity (\%) & & & 0.21 & & & 0.41 & 0.26 \\
\hline Caucasian & $484(79.1)$ & $14(66.7)$ & & $476(75.3)$ & $56(66.7)$ & & \\
\hline Asian (+Sri Lanka, China) & $59(9.6)$ & $5(23.8)$ & & $49(7.8)$ & $8(9.5)$ & & \\
\hline African & $28(4.6)$ & 0 & & $67(10.6)$ & $12(14.6)$ & & \\
\hline Latin American & $11(1.8)$ & 0 & & $10(1.6)$ & $1(1.2)$ & & \\
\hline Indian (+Pakistan, Bangladesh) & $15(2.5)$ & $2(9.5)$ & & $16(2.5)$ & $5(6.1)$ & & \\
\hline Other & $15(2.5)$ & 0 & & $14(2.2)$ & $2(2.2)$ & & \\
\hline Parity $\geq 1$ (\%) & $310(50.6)$ & $11(52.4)$ & 1.00 & $322(50.9)$ & $46(54.8)$ & 0.59 & 1.00 \\
\hline
\end{tabular}

Data is presented as mean \pm standard deviation (SD), number (percentage); BMI=body mass index, GDM=gestational diabetes mellitus, $\mathrm{y}=$ years. 
Table 3: Pregnancy outcomes of study groups in both periods.

\begin{tabular}{|c|c|c|c|c|c|c|c|}
\hline \multirow{2}{*}{$\begin{array}{l}\text { Period } \\
\text { Study group }\end{array}$} & \multicolumn{3}{|c|}{ Period $1(n=647)$} & \multicolumn{3}{|c|}{ Period $2(n=720)$} & \multirow{2}{*}{$\begin{array}{l}\begin{array}{l}\text { Comparison of GDM } \\
\text { groups in period } 1 / 2\end{array} \\
\text { P-value }\end{array}$} \\
\hline & $\begin{array}{l}\text { No GDM } \\
(n=626)\end{array}$ & $\begin{array}{r}\text { GDM } \\
(n=21)\end{array}$ & P-value & $\begin{array}{l}\text { No GDM } \\
(n=635)\end{array}$ & $\begin{array}{r}\text { GDM } \\
(n=85)\end{array}$ & P-value & \\
\hline Treatment & NA & & NA & NA & & NA & \\
\hline $\begin{array}{l}\text { Diet } \\
\text { Insulin }\end{array}$ & & $\begin{array}{r}13(61.9) \\
8(38.1)\end{array}$ & & & $\begin{array}{l}60(70.6) \\
25(29.4)\end{array}$ & & 0.12 \\
\hline $\begin{array}{l}\text { GA at delivery, weeks (SD } \\
\text { in days) }\end{array}$ & $39+4(14)$ & $39+3(6)$ & 0.75 & $39+2(19)$ & $38+6(21)$ & 0.22 & 0.62 \\
\hline$<37$ weeks & $27(4.4)$ & $2(9.5)$ & 0.25 & $57(9.0)$ & $8(9.8)$ & 1.00 & 0.37 \\
\hline Mode of delivery (\%) & & & 0.04 & & & 0.008 & 0.87 \\
\hline $\mathrm{CD}$, primary & $64(10.5)$ & $7(33.3)$ & & $102(16.1)$ & $23(27.4)$ & & \\
\hline$C D$, secondary & $93(15.2)$ & $1(4.8)$ & & $102(16.1)$ & $14(16.7)$ & & \\
\hline OVD & $111(18.2)$ & $1(4.8)$ & & $98(15.5)$ & $8(9.5)$ & & \\
\hline Preeclampsia (\%) & $13(2.1)$ & $2(9.5)$ & 0.15 & $10(1.6)$ & $2(2.4)$ & 0.64 & 0.37 \\
\hline Birth weight (g) & $3379(582)$ & $3573(589)$ & 0.15 & $3320(635)$ & $3348(735)$ & 0.74 & 0.42 \\
\hline Macrosomia ( $\geq 4000 \mathrm{~g}$ ) (\%) & $72(11.8)$ & $5(23.8)$ & 0.16 & $72(11.4)$ & $15(17.9)$ & 0.13 & 0.66 \\
\hline LGA ( $\geq 90^{\text {th }}$ percentile) $(\%)$ & $25(4.1)$ & $3(14.3)$ & 0.06 & $28(4.4)$ & $8(9.5)$ & 0.06 & 0.83 \\
\hline \multicolumn{8}{|l|}{ Infant outcome (\%) } \\
\hline Cord $\mathrm{pH}<7.0$ & $3(0.6)$ & 0 & 1.00 & $2(0.3)$ & $1(1.4)$ & 0.30 & 1.00 \\
\hline Shoulder dystocia & $2(0.4)$ & 0 & 1.00 & $1(0.2)$ & 0 & 1.00 & 1.00 \\
\hline Perinat. mortality & $5(0.9)$ & 0 & 1.00 & $3(0.5)$ & $1(1.2)$ & 1.00 & 0.66 \\
\hline Hypoglycemia & $58(9.6)$ & $5(25.0)$ & 0.046 & $38(6.3)$ & $21(26.3)$ & $<0.001$ & 0.76 \\
\hline
\end{tabular}

Data is presented as mean \pm standard deviation (SD), number (percentage); $C D=$ cesarean delivery, $G D M=$ gestational diabetes mellitus, $\mathrm{LGA}=$ large for gestational age, $\mathrm{NA}=$ not applicable, $\mathrm{OVD}=$ operative vaginal delivery, $\mathrm{RDS}=$ respiratory distress syndrome; weeks=weeks (of gestation).

between women with and without GDM. No differences were found in rate of preeclampsia, asphyxia, shoulder dystocia or perinatal mortality. Infants of mothers with GDM $\geq 34$ weeks of gestation showed a higher rate of hypoglycemia after delivery compared to those born to women without GDM (period 1: $25 \%$ vs. 10\%, $\mathrm{P}=0.046$; period 2: $26 \%$ vs. $6 \%, \mathrm{P}<0.001)$.

\section{Discussion}

The aim of this study was to evaluate the effect of the new IADPSG guidelines for screening and diagnosis of GDM on GDM prevalence in a cohort from a single Swiss tertiary hospital. Instead of administering two screening methods to one period as previously reported we studied two screening periods with different screening approaches. The introduction of the new IADPSG criteria resulted in an absolute increase in GDM prevalence of $8.5 \%$ (3.3\% in period 1 to $11.8 \%$ in screening period 2), which represents an almost fourfold increase in prevalence. This observation is consistent with the previously reported rise in prevalence in most western countries [12, 13]. Our and the mentioned rates of GDM prevalence in a mainly
Caucasian population was lower than the prevalence of $17.8 \%$ in the HAPO study, in which approximately 25,000 pregnant women in four different continents participated [1]. In a sub-analysis of the HAPO study, a great variation in GDM frequencies was found from 9.3 to $25.5 \%$ and differed between collaborating centers [14].

Ten percent of women with GDM in screening period 1 and $22 \%$ in screening period 2 could be detected in early pregnancy using the $75 \mathrm{~g}$ OGTT, if multiple risk factors were taken into account. The awareness for early GDM screening was much higher in our hospital after the introduction of the IADPSG criteria. The screening approach resulted in earlier treatment through diet or with insulin in these women. This might be of benefit for the short and long term outcome of mother and child.

In screening period 2, the proportion of GDM cases dependent on each threshold showed similar results as reported in the HAPO study [1, 2]. In our cohort, $49 \%$ of women were diagnosed with GDM by an elevated fasting glucose value vs. $52 \%$ in the HAPO study, and $35 \%$ and $15 \%$ by abnormal $1-$ and 2 -h values vs. $35 \%$ and $13 \%$ in the HAPO study, respectively.

The proportion of women with insulin dependent GDM was decreased from 38\% in screening period 1-29\% 
in screening period 2. This reduction was not statistically significant, possibly due to the sample size. The necessity of insulin therapy was high in both screening periods. The proportion of women who required insulin therapy in screening period 2 corresponded with the currently reported rates of insulin dependent GDM of around 25\% [3]. Although not significant, the percentage of treated women with insulin therapy decreases slightly in period 2, which means that with the lower cut-off thresholds, the medical community does not treat the same amount of women medically, but continues to put an accent on lifestyle changes.

Despite the GDM diagnosis and a substantially higher pre-pregnancy BMI in GDM women, maternal weight gain was 1.6-1.7 kg less in GDM women in period 1 and 2. Additionally, birthweight and prevalence of macrosomia and LGA were relatively low. These observations possibly result from the great effect of the nutritional counseling and insulin treatment in GDM women.

Women with GDM were more likely to have a planned primary cesarean section than women without GDM in both periods (33\% in screening period 1 and $27 \%$ in screening period 2). The major factors contributing to the high primary cesarean section rate were due to the maternal wish, fear of complications (macrosomia, high blood loss or perineal trauma, traumatic delivery experience) and unsuccessful labor induction, but probably not created through "doctor induced medicalization" due to higher prevalence of GDM diagnosis.

Two prospective interventional trials showed that treatment of mild hyperglycemia similar to those women detected by IADPSG criteria could significantly reduce the rate of macrosomia, shoulder dystocia, cesarean section, preeclampsia and maternal weight gain [15] and lower the rate of serious perinatal complications such as intrauterine death, neonatal mortality, shoulder dystocia, nerve damage or bone fracture as well as macrosomia and preeclampsia [16]. But our cohort detected more women which were detected by even less stringent glucose thresholds as in both reported studies. A decrease in neonatal and maternal adverse events could not be shown in our study due to the limited number of women. The rate of LGA was similar in the group diagnosed with GDM according to IADPSG criteria with $9.5 \%$ as previously reported [17]. The incidence of preeclampsia, arterial cord blood $\mathrm{pH}<7.0$, shoulder dystocia and perinatal mortality were rare and there were no statistically significant differences between the two periods and GDM groups.

Neonatal hypoglycemia $<2.5 \mathrm{mmol} / \mathrm{L}$ occurred in $25 \%$ and $26 \%$ of infants born to mothers with GDM versus $10 \%$ and $6 \%$ of infants born to healthy mothers in screening period 1 and 2, respectively. The prevalence of 25-26\% in neonates of mothers with GDM coincides with previously published data by Sakar et al. [18]. The prevalence of hypoglycemia in term infants was reported to be $12 \%$ in an early study in 1992 [19]. It should be noted that our findings might partially be caused by detection bias, attributed to the fact that infants born to diabetic mothers are more likely to be closely monitored than normal neonates. In our center, all infants at increased risk for hypoglycemia are monitored frequently and treated early from the first $\mathrm{h}$ of life onwards with enteral feeds of breast milk according to the guidelines of the Swiss Society of Neonatology to prevent hypoglycemia by promoting gluconeogenesis [20]. However, even with treatment of the mothers, the rate of neonatal hypoglycemia and thus fetal exposure to maternal hyperglycemia stays high and were similar in GDM groups of both periods.

To our knowledge, this study examines the impact of the new IADPSG criteria in a Swiss cohort for the first time. Therefore we used a retrospective approach to include the previous two-step screening approach and compared the two-step to the one-step screening test recommended by the IADPSG in 2010 [1]. The retrospective nature of the study limited the possibility of data acquisition. Another limitation of the study is the lack of multivariable logistic regression analysis to determine whether the degree of glucose tolerance had an impact on the adverse pregnancy outcomes. This was due to the low number of adverse events in both periods. The essential issue, whether women which were not diagnosed with the previous screening (period 1), but are now diagnosed with the current screening (period 2), had a better maternal and offspring short- and long-term outcome when treated, could not be elucidated with our study.

The debate about the new IADPSG criteria is ongoing. Some authors think that adopting the IADPGS criteria might be less beneficial [21-23]. Firstly, especially minor glucose abnormalities are likely to be detected. Secondly, the diagnostic test using a single OGTT $75 \mathrm{~g}$ shows low reproducibility. Thirdly, the evidence for a treatment benefit in these mild cases is weak. On the other hand, supporters of the new IADPSG criteria emphasize that implementation of lifestyle modifications even in women with mild GDM will change nutritional and exercise behavior positively and might improve acceptance of postdelivery counseling to reduce the future diabetes risk. The reduction of diabetes type 2 in the mothers might then be cost effective [24].

In conclusion, the adoption of the new IADPSG criteria resulted in a considerable and expected increase in GDM diagnosis in our single center Swiss cohort. Due 
to the small numbers of adverse events in our screening periods, improvements in outcome for mothers and their neonates could not be detected. Further randomized controlled trials are needed to investigate whether treatment of additionally diagnosed mothers with GDM might improves short-term as well as long-term outcomes, including cost-effectiveness analyses.

Acknowledgments: We would like to thank Dorothy Huang for critical proofreading the English.

Contribution to authorship: E.A. Huhn, N. Massaro, and S Streckeisen contributed to acquisition of data. E.A. Huhn and N. Massaro are responsible for the study design and are equally contributing authors. A. Schoetzau carried out the statistical analysis and contributed to the manuscript. O. Lapaire composed the manuscript together with E.A. Huhn. G. Manegold-Brauer, I. Hoesli, S. Schulzke and B. Winzeler made important contributions and critically reviewed the content.

Disclosure of interests: The authors declare that there are no further financial or personal relationships with other people or organizations that could inappropriately influence the work reported or the conclusions, implications, or opinions stated.

Funding: This study had no financial funding.

\section{References}

[1] International Association of Diabetes and Pregnancy Study Groups Consensus Panel, Metzger BE, Gabbe SG, Persson B, Buchanan TA, Catalano PA, et al. International association of diabetes and pregnancy study groups recommendations on the diagnosis and classification of hyperglycemia in pregnancy. Diabetes Care. 2010;33:676-82.

[2] HAPO Study Cooperative Research Group, Metzger BE, Lowe LP, Dyer AR, Trimble ER, Chaovarindr U, et al. Hyperglycemia and adverse pregnancy outcomes. N Engl J Med. 2008;358:19912002.

[3] Lehmann R, Troendle A, Brändle M. [New insights into diagnosis and management of gestational diabetes mellitus: recommendations of the Swiss Society for Endocrinology and Diabetes]. Ther Umsch. 2009;66:695-706.

[4] Boulvain M, Brändle M, Drack G, Hoesli I, Honegger C, Lehmann, R, et al. Expertenbrief No 37 "Screening des Gestationsdiabetes.” 2011. http://www.sggg.ch/fileadmin/ user_upload/Dokumente.

[5] American Diabetes Association. Standards of medical care in diabetes - 2013. Diabetes Care. 2013;36(Suppl 1):S11-66.

[6] Diagnostic criteria and classification of hyperglycaemia first detected in pregnancy: a World Health Organization Guideline. Diabetes Res Clin Pract. 2014;103:341-63.

[7] Agarwal MM, Dhatt GS, Othman Y. Gestational diabetes: differences between the current international diagnostic criteria and implications of switching to IADPSG. J Diabetes Complications. 2015;29(4):544-9.

[8] Visser GHA, de Valk HW. Management of diabetes in pregnancy: antenatal follow-up and decisions concerning timing and mode of delivery. Best Pract Res Clin Obstet Gynaecol. 2015;29:237-43.

[9] ACOG Committee on Practice Bulletins-Gynecology, The American College of Obstetrician and Gynecologists. ACOG practice bulletin clinical management guidelines for obstetrician-gynecologists. Number 40 (Shoulder Dystocia), November 2002. Obstet Gynecol. 2002;100(5 Pt 1):1045-50.

[10] Rasmussen KM, Catalano PM, Yaktine AL. New guidelines for weight gain during pregnancy: what obstetrician/ gynecologists should know. Curr Opin Obstet Gynecol. 2009;21:521-6.

[11] R Development Core Team R. R: a language and environment for statistical computing. R Found Stat Comput. 2014;1:409.

[12] O'Sullivan EP, Avalos G, O'Reilly M, Dennedy MC, Gaffney G, Dunne F. Atlantic Diabetes in Pregnancy (DIP): The prevalence and outcomes of gestational diabetes mellitus using new diagnostic criteria. Diabetologia. 2011;54:1670-5.

[13] Mayo K, Melamed N, Vandenberghe H, Berger H. The impact of adoption of the international association of diabetes in pregnancy study group criteria for the screening and diagnosis of gestational diabetes. Am J Obstet Gynecol. 2015;212:224.e1-9.

[14] Sacks DA, Hadden DR, Maresh M, Deerochanawong C, Dyer $A R$, Metzger BE, et al. Frequency of gestational diabetes mellitus at collaborating centers based on IADPSG consensus panel-recommended criteria: the Hyperglycemia and Adverse Pregnancy Outcome (HAPO) Study. Diabetes Care. 2012;35:526-8.

[15] Landon MB, Spong CY, Thom E, Carpenter MW, Ramin SM, Casey B, et al. A multicenter, randomized trial of treatment for mild gestational diabetes. N Engl J Med. 2009;361:1339-48.

[16] Crowther CA, Hiller JE, Moss JR, McPhee AJ, Jeffries WS, Robinson JS. Effect of treatment of gestational diabetes mellitus on pregnancy outcomes. N Engl J Med. 2005;352:2477-86.

[17] Bodmer-Roy S, Morin L, Cousineau J, Rey E. Pregnancy outcomes in women with and without gestational diabetes mellitus according to the International Association of the Diabetes and Pregnancy Study Groups criteria. Obstet Gynecol. 2012;120:746-52.

[18] Sarkar S, Watman J, Seigel WM, Schaeffer HA. A prospective controlled study of neonatal morbidities in infants born at 36 weeks or more gestation to Women with dietcontrolled gestational diabetes (GDM-class Al). J Perinatol. 2003;23(3):223-8.

[19] Hawdon JM, Ward Platt MP, Aynsley-Green A. Patterns of metabolic adaptation for preterm and term infants in the first neonatal week. Arch Dis Child. 1992;67(4 Spec No):357-65.

[20] Berger TM, Das-Kundu S, Pfister RE, Pfister R, Stocker M, Zimmermann U. Prevention and therapy of hypoglycemia in infants with a gestational age above $340 / 7$ weeks in maternity wards. 2007: http://www.neonet.ch/ files/3014/2597/8497/2007_Hyp.

[21] Cundy T, Ackermann E, Ryan EA. Gestational diabetes: new criteria may triple the prevalence but effect on outcomes is unclear. Br Med J. 2014;348:g1567. 
[22] Cundy T. Proposed new diagnostic criteria for gestational diabetes - a pause for thought? Diabet Med. 2012;29:176-80.

[23] Ryan EA. Diagnosing gestational diabetes. Diabetologia. 2011;54:480-6.

[24] Werner EF, Pettker CM, Zuckerwise L, Reel M, Funai EF, Henderson J, et al. Screening for gestational diabetes mellitus: are the criteria proposed by the International Association of the Diabetes and Pregnancy Study Groups Cost-Effective? Diabetes Care. 2012;35:529-35.

The authors stated that there are no conflicts of interest regarding the publication of this article. 